\title{
Objective Structured Examinations as Supplemental Equipment for Amending Emotional Intelligence: A Pilot Survey
}

\author{
Saeed Shoja Shafti* \\ University of Social Welfare and Rehabilitation Sciences (USWR), Razi Psychiatric Hospital, Iran \\ *Corresponding author: Saeed Shoja Shafti, Full Professor of Psychiatry, University of Social Welfare and Rehabilitation Sciences \\ (USWR), Razi Psychiatric Hospital, Iran
}

\begin{abstract}
Background: The scientific study of emotional intelligence (EI) in organizations has gained considerable research activity over recent years because it is being concerned with awareness and management of one's own feelings and emotions in daily living activities. The objective of the present study was to investigate the relationship between EI of a group of psychiatric residents and their academic achievement to see that whether proper training and evaluation by new educative instruments can recompense any degree of shortage in EI.
\end{abstract}

Methods: Consistent with a cross-sectional survey design, 31 psychiatric residents had been requested to answer to The Schutte Self Report Emotional Intelligence Test (SSEIT), in June 2014, for examining the situation with respect to objective structured examinations, like mini-Clinical Examination Exercise (mini-CEX), Objective Structured Clinical Examination (OSCE), and chartstimulated recall (CSR) scores, which had been taken in the earlier 6 months. SSEIT score of 90 had been taken as demarcating point for dividing the sample population into two parallel groups, including the first group with SSEIT score lower than 90 and second group with SSEIT score equal to or more than 90.

Results: The response rate was 93.54\%. In line with the results, there was no meaningful relationship between the aforesaid first group and second group as regards the relationship between SSEIT's score and the mean total score of Mini-CEX, OSCE, and CSR, which had been examined in the preceding 6 months.

Conclusion: The current study demonstrates that EI does not seem to be a fixed problem in psychiatric residents, and enough exercise along with improvement of necessary interrogating or clinical skills may improve or compensate for unsatisfactory EI.

Keywords: Emotional Intelligence; Objectives Structural Examinations; Psychiatric Residents

\section{Introduction}

The scientific study of Emotional Intelligence (EI) in organizations has gained considerable research activity over recent years [1]. Simultaneously researchers have investigated and raised concerns about the appropriate way to measure EI in various studies [2]. Although EI has been the subject of much attention at both popular and academic level, only now are answers provided to some of the fundamental questions posed about the construct [3]. Dulewicz, Higgs and Slaski confirm that in literature there appears to be some debate about what constitutes the domain of EI, about terminology used to describe the construct and about methods used to measure it [4]. One method that has been used widely in research to measure
EI is the Schutte Emotional Intelligence Scale (SEIS) [5]. Dulewicz et al. state that EI is not a new concept [4]. Mayer, Salovey and Caruso [6] define the concept of EI as the capacity to reason about emotions, and of emotions to enhance thinking. EI includes the abilities to accurately perceive emotions, to access and generate emotions in order to assist thoughts, to understand emotions and emotional knowledge, and to reflectively regulate emotions in order to promote emotional and intellectual growth [6]. Dulewicz and Higgs [4] define EI as being concerned with being aware of and managing one's own feelings and emotions; being sensitive to and influencing others; sustaining one's motivation; and balancing one's motivation 
and drive with intuitive, conscientious and ethical behavior. It is apparent that from this theoretical perspective EI refers specifically to the co-operative combination of intelligence and emotion [7]. EI emphasizes the importance of self-awareness and understanding, redressing a perceived imbalance between intellect and emotion in the life of the collective Western mind [7]. Zeidner et al. further state that EI also connects with several cutting-edge areas of psychological science, including the neuroscience of emotion, self-regulation theory, studies of meta-cognition, and the search for human cognitive abilities beyond 'traditional' academic intelligence. Given the core proposition that it is a combination of IQ and EI that determines life success, a question arises as to whether or not it is feasible to measure EI [4]. On the other hand, an Objective Structured Clinical Examination (OSCE) is a modern type of examination often used in health sciences (e.g. Midwifery, orthoptics, optometry, medicine, naturopathic medicine, physician assistants/associates, physical therapy, radiography, nursing, pharmacy, dentistry, chiropractic medicine, paramedicine, podiatry, veterinary medicine). It is designed to test clinical skill performance and competence in skills such as communication, clinical examination, medical procedures / prescription, exercise prescription, joint mobilization / manipulation techniques, radiographic positioning, radiographic image evaluation and interpretation of results [8]. Simulation is a new exciting technology incorporated in undergraduate medical curriculum. It is well accepted by educators across the world to improve experiential learning by enhancing the performance of medical professionals [9]. Simulation is defined as imitation of the "real world" setting to model the environment, resources needed, and the people involved [10]. Educators have encountered educational challenges by reforming the curriculum, developing problem-based learning, and promoting research as well as independent learning. Nevertheless, disparity still persists between the preclinical and clinical environment. Preclinical medical students have minimal contact with clinical cases and are apprehensive when they commence their clinical years and internship. Many students feel that they are inefficient in history taking, physical examination, diagnosis, and management. Medical simulation has been adopted to bridge this educational gap and provide an opportunity to learn from errors [11]. The objective of the present study is to investigate the relationship between EI of a group of psychiatric residents and their academic achievement to see that whether proper training and evaluation by new educative instruments can recompense any degree of shortage in EI.

\section{Methods}

A cross-sectional appraisal scheme was used in the present assessment. Psychiatric residents were informed about the objective and method of the study, voluntary format of contribution, anonymity and privacy of information. The study was accomplished during June 2014. Total existing population of psychiatric residents was selected as the sample for this study $(n=31)$. Among the total 31 psychiatric residents, 29 participants (93.54\%) responded to the evaluation. While one of the participants was reluctant to participate in the assessment, another one was absent during the assessment. Two different types of tools were used in the current estimation. The first one was a demographic inquiry form that involved four queries of sex, age, year of training and educational outcomes regarding their objective structured examinations, including Mini-Clinical Examination Exercise (Mini- CEX), Objective Structured Clinical Examination (OSCE), and Chart-Stimulated Recall (CSR) scores. It deserves to be mentioned that Mini-CEX is a method of appraisal that can be used to evaluate the clinical skill of residents and can enhance student learning and develop student professionalism in serving patients [12]. CSR, as well, has been utilized by active specialists in medicine as a reliable and valid instrument to find strengths and weaknesses in medical practice [13]. OSCE, too, is a modern form of scrutiny that is planned to test clinical skills such as clinical examination, communication, medical procedures / prescription, etc. [14]. The second instrument involved the Schutte Self Report Emotional Intelligence Test (SSEIT), which was developed by Schutte et al. [5]. This tool measures trait EI by means of 33 self-referencing items that evaluate EI level of the person. Individuals score the level they agree or disagree with every single announcement on a 5-point measure oscillating between 1 (strongly disagree) and 5 (strongly agree). Three items among the thirty-three ones [15], are inversely scored. According to Schutte et al., while the two-week test-retest reliability co-efficient of SSEIT is around 0.78 , the scale has high internal consistency with Cronbach's alpha $(\alpha)$ ranging from 0.87 to 0.90 (31). SSEIT scale has been used in different studies with a range of samples including adolescents, adults, and secondary school apprentices, and it is easy to apprehend and score [5]. SSEIT score of 90 is usually taken as a cut-off point. While SSEIT score of 90 or higher includes: low average (90-99), high average (100-109), competent (110-119), strength (120-129) and significant strength (130+), SSEIT score of 89 and lower consists of: consider improvement (70-89) and consider development (69 or less), based on Mayer's guidelines [15].

\section{Statistical Analysis}

Demographic characteristics were analyzed by comparison of proportions regarding gender and year of study and comparison of means (t-test) regarding age, scholastic evaluative scores and EI. Data analysis was conducted using MedCalc Statistical Software version 15.2. Statistical significance was determined as a $\mathrm{P} \leq 0.05$.

\section{Results}

The demographic characteristics of the study participants are described below in Table 1, and there was no significant baseline demographic difference between male and female participants regarding ethnicity, quantity, age and SSEIT score (Table 1). Among 31 psychiatric residents of the University of Social Welfare and Rehabilitation Sciences, 29 participants (93.54\%) answered back to the survey and replied to the Schutte Self Report Emotional Intelligence Test in June 2014.0ne of the residents was reluctant to participate and another one was on leave during the assessment. $17.24 \%(n=5), 27.58 \%(n=8), 24.13 \%(n=7)$ and $31.03 \%(n=9)$ of the participants were $1^{\text {st }}$ year, $2^{\text {nd }}$ year, $3^{\text {rd }}$ year and finally $4^{\text {th }}$ year post graduate trainee, respectively (Table 2). According to the findings and based on ANOVA, there was no significant difference 
among four groups of participants with respect to the SSEIT scores (Table 3). In the current evaluation, SSEIT score of 90 was taken as a demarcating point. As a result, while SSEIT score of 90 or higher could include: Low average (90-99), High average (100109) , Competent (110-119), Strength (120-129) and Significant Strength(130+), SSEIT score of 89 and lower as well could consist Consider Improvement (70-89) and Consider Development (69 or less), based on Mayer's guidelines (Mayer, et al., 2002, p. 18). On the whole, in the present sample population, $34.48 \%(n=11)$ of the participants had SSEIT score of 89 or lesser (first target group, with a SSEIT score of $83.45+/-3.98)$, and $79.31 \%(n=18)$ of the contributors had SSEIT score of 90 or higher (second target group, with a SSEIT score of 101.5+/-9.03) (Table 4). While quantitatively and base on 'Comparison of Proportions' there was no significant difference among those two target groups $(\mathrm{z}=-1.8383, \mathrm{p}<0.06, \mathrm{C}$ I $95 \%=-0.49,0.01)$, comparison of means showed a significant difference, with respect to SSEIT score, among them $(\mathrm{p}<0.000)$ (Table 4). But as the main objective of the present assessment and based on between-group analysis and comparison of means, while the mean total scores of the $2^{\text {nd }}$ Group ( with SSEIT score $=$ or $>90$ ) was commonly higher than the first group (with SSEIT score <90) in objective structured examinations, including Mini-CEX, OSCE and CSR , no significant difference was evident among those two target groups regarding their performance in those objective educational tools for assessment of trainee's skills $(\mathrm{p}<0.10, \mathrm{p}<0.09, \mathrm{p}<0.16$, respectively) (Table 5). Post-hoc power analysis showed a power equal to 0.36 on behalf of this trial, which turned to power $=0.74$ in compromised power analysis.

Table 1: Demographic characteristics of participants.

\begin{tabular}{|c|c|c|c|c|c|c|}
\hline Demographic Variables & Male & Female & $\mathbf{z}$ & $\mathbf{t}$ & $\mathbf{p}$ & CI \\
\hline Gender & $\mathrm{N}=12(41.37 \%)$ & $\mathrm{N}=17(58.62 \%)$ & -1.3131 & & 0.1892 & $-0.4298,0.0849$ \\
\hline Age & $34.5 \pm 4.90$ & $33.23 \pm 4.43$ & & 0.728 & 0.4729 & $-2.31,4.85$ \\
\hline Mean SSEIT score & $95 \pm 5.67$ & $96 \pm 5.24$ & & -0.489 & 0.6285 & $-5.19,3.19$ \\
\hline
\end{tabular}

Table 2: SSEIT score of participants.

\begin{tabular}{|c|c|c|c|c|}
\hline $\begin{array}{l}\text { Year of Study } \\
\text { Participants }\end{array}$ & $\begin{array}{c}1^{\text {st }} \text { Year } n=5 \\
(17.24 \%)\end{array}$ & $\begin{array}{c}2^{\text {nd }} \text { Year } n=8 \\
(27.58 \%)\end{array}$ & $\begin{array}{c}3^{\text {rd }} \text { Year } n=7 \\
(24.13 \%)\end{array}$ & $\begin{array}{c}4^{\text {th }} \text { Year n=9 } \\
(31.03 \%)\end{array}$ \\
\hline No. 1 & 85 & 91 & 96 & 88 \\
\hline No. 2 & 89 & 99 & 79 & 99 \\
\hline No. 3 & 90 & 105 & 78 & 114 \\
\hline No. 4 & 116 & 118 & 85 & 104 \\
\hline No. 5 & 107 & 81 & 111 & 98 \\
\hline No. 6 & - & 84 & 109 & 78 \\
\hline No. 7 & - & 89 & 92 & 90 \\
\hline No. 8 & - & 93 & - & 82 \\
\hline No. 9 & - & - & - & 95 \\
\hline Mean SSEIT score & $97.4 \pm 11.97$ & $95.12 \pm 11.21$ & $92.85 \pm 12.39$ & $94.22 \pm 10.50$ \\
\hline
\end{tabular}

Table 3: Comparison of SSEIT score between four groups by means of ANOVA.

\begin{tabular}{|c|c|c|c|c|c|c|}
\hline \multicolumn{7}{|c|}{ Anova: Single Factor } \\
\hline \multicolumn{7}{|c|}{ Summary } \\
\hline Groups & Count & Sum & Average & \multicolumn{3}{|c|}{ Variance } \\
\hline Column 1 & 5 & 487 & 97.4 & \multicolumn{3}{|c|}{179.3} \\
\hline Column 2 & 8 & 760 & 95 & \multicolumn{3}{|c|}{145.428} \\
\hline Column 3 & 7 & 650 & 92.857 & \multicolumn{3}{|c|}{179.142} \\
\hline Column 4 & 9 & 848 & 94.222 & \multicolumn{3}{|c|}{124.194} \\
\hline \multicolumn{7}{|c|}{ Anova } \\
\hline Source of Variation & SS & $\mathrm{df}$ & MS & $\mathrm{F}$ & P-value & F crit \\
\hline Between Groups & 62.939 & 3 & 20.979 & 0.137 & 0.936 & 2.991 \\
\hline Within Groups & 3803.613 & 25 & 152.144 & & & \\
\hline Total & 3866.552 & 28 & & & & \\
\hline
\end{tabular}

Citation: Saeed Shoja Shafti. Objective Structured Examinations as Supplemental Equipment for Amending Emotional Intelligence: A 
Table 4: Comparison of means between groups with lower and higher SSEIT score.

\begin{tabular}{|c|c|c|c|c|c|}
\hline Target Groups & $1^{\text {st }}$ Group & $2^{\text {nd }}$ Group & \multirow{2}{*}{$\mathbf{t}$} & \multirow{2}{*}{$\mathbf{p}$} & \multirow{2}{*}{ CI } \\
\hline Participants & SSEIT score $<90 \mathrm{n}=11(34.48 \%)$ & SSEIT score $=$ or $>90 \mathrm{n}=18(79.31 \%)$ & & & \\
\hline No.1 & 85 & 91 & & & \\
\hline No.2 & 89 & 99 & & & \\
\hline No.3 & 81 & 105 & & & \\
\hline No.4 & 84 & 118 & & & \\
\hline No.5 & 89 & 99 & & & \\
\hline No.6 & 79 & 114 & & & \\
\hline No.7 & 78 & 104 & & & \\
\hline No.8 & 85 & 93 & & & \\
\hline No.9 & 88 & 96 & & & \\
\hline No.10 & 78 & 90 & & & \\
\hline No.11 & 82 & 116 & & & \\
\hline No.12 & & 107 & & & \\
\hline No.13 & & 111 & & & \\
\hline No.14 & & 109 & & & \\
\hline No.15 & & 92 & & & \\
\hline No.16 & & 98 & & & \\
\hline No.17 & & 90 & & & \\
\hline No.18 & & 95 & & & \\
\hline Mean & 83.45 & 101.5 & -6.236 & 0 & $-23.99,-12.11$ \\
\hline SD & 3.98 & 9.03 & & & \\
\hline
\end{tabular}

Table 5: Comparative analysis of different scholastic evaluative scores between groups with lower and higher SSEIT score.

\begin{tabular}{|c|c|c|c|c|c|}
\hline SSEIT score & $1^{\text {st }}$ Group & $2^{\text {nd }}$ Group & & & \\
\hline Objective structured examinations & SSEIT score $<90 \mathrm{n}=11(34.48 \%)$ & SSEIT score $=$ or $>90 \mathrm{n}=18(79.31 \%)$ & $\mathrm{l}$ & $\mathbf{p}$ & 4 \\
\hline Mean total score of Mini-CEX & $22.46 \pm 3.82$ & $24.78 \pm 3.42$ & 1.66 & 0.1 & $-5.17,0.53$ \\
\hline Mean total score of OSCE & $24.44 \pm 3.11$ & $26.61 \pm 3.27$ & 1.72 & 0.09 & $-4.75,0.41$ \\
\hline Mean total score of CSR & $19.18 \pm 3.51$ & $21.36 \pm 4.09$ & 1.42 & 0.16 & $-5.31,0.95$ \\
\hline
\end{tabular}

\section{Discussion}

Simulation based education is a promising discipline that provides secure and effectual learning platform for students. The clinical sessions can be planned, observed and repeated to facilitate learning [16]. Exposure to simulation for medical students is a valuable tool to enhance knowledge and student self-confidence at a key transition period prior to beginning of internship [16]. Students report difficulty in applying theoretical knowledge and perceive shortcomings in integrating basic science knowledge with clinical practice [17]. Imparting medical knowledge and skills without placing a patient at an increased risk of complications can be attained through simulation sessions for undergraduate medical students who do not have complete autonomy in diagnosis and management of clinical cases [18]. One of the most challenging aspects of teaching residents is identifying tools for assessment for learning. Assessment for learning allows teachers to see where their residents are doing well and where they need further instruction; as well, it allows teachers to target instruction during the assessment to further residents' understanding [19]. An OSCE, as the prototype of such kind of innovative evaluations, usually comprises a circuit of short (the usual is 5-10 minutes although some use up to 15 minute) stations, in which each candidate is examined on a one-to-one basis with one or two impartial examiner(s) and either real or simulated patients (actors or electronic patient simulators). Each station has a different examiner, as opposed to the traditional method of clinical examinations where a candidate would be assigned to an examiner for the entire examination. Candidates rotate through the stations, completing all the stations on their circuit. In this way, all candidates take the same stations. It is considered to be an improvement over traditional examination methods because the stations can be standardized enabling fairer peer comparison and complex procedures can be assessed without endangering patient's health. As the name suggests, an OSCE is designed to be objective (all candidates are assessed using exactly the same stations (although if real patients are used, their signs may vary slightly) with the same marking scheme, structured (stations in OSCEs have 
a very specific task. Where simulated patients are used, detailed scripts are provided to ensure that the information that they give is the same to all candidates, including the emotions that the patient should use during the consultation.

Instructions are carefully written to ensure that the candidate is given a very specific task to complete, and, finally, clinicaloriented (the OSCE is designed to apply clinical and theoretical knowledge. Where theoretical knowledge is required, for example, answering questions from the examiner at the end of the station, then the questions are standardized and the candidate is only asked questions that are on the mark sheet and if the candidate is asked any others then there will be no marks for them) $[20,21]$. So, competent performance requires not only requisite knowledge and skills but also beliefs of personal efficacy to use both effectively. Anyhow, the relationship between clinical experience and student performance is complex. Well-organized and strategic learning styles appear to influence the benefits of increased clinical exposure. Direct observation of clinical skills is a critical first step in helping trainees to improve their clinical skills [22]. Back to our discussion and according to the findings of the present assessment, while significant difference was palpable between two groups of psychiatric residents regarding emotional intelligence, based on SSEIT score, no significant correlation was evident between that factor and academic performance of participants. Such a result may not be in harmony with the suggestion of Carrothers et al. [23] who had suggested using EI as part of the selection process for medical students and Stratton et al. [24], who stated that Individuals with low levels of EI may lack the ability to relate empathetically with patients as they are unable to recognize feelings, distress, and mood , or belief of McQueen [25] who said that low levels of EI leads to a negative impact on the doctor-patient relationship . In contrast, our finding was more in agreement with Stratton et al. [24] who found only a modest correlation between EI, and students' clinical skills assessed by standardized patients in an Objective Structured Clinical Examination (OSCE). On the other hand it could not deny the view of Arora et al. [26] who noted that higher EI may play a role in maintaining good physician-patient relationships, improved teamwork and communication skills, better stress management, and superior commitment and leadership, since generally higher scores in the aforesaid objective assessments were observable, as well, in the present assessment and in the group with higher SSEIT score, though non-significantly. On the other hand, non-significant difference between two groups regarding objective assessment tools could be attributed to the preparation of psychiatric residents, from the start, respecting basic principles and techniques of interview, in general, and sympathy, rapport, verbal and non-verbal communication, specially.

Such an inference is in harmony with the standpoint of Stoller et al. [27] who had recommended that a spiral curriculum should be used to develop EI skills of physicians. Also, while Austin et al. [28] found a gender-based difference and significantly higher overall EI and empathy in female medical students, as like as Carrothers et al. [23], in the present assessment as well higher SSEIT score was evident in female residents, but it was not a significant variance. Such discrepancies may necessitate taking into consideration other interconnected factors that may easily be ignored during scientific assessments, as like as culture, which has been declared by Cherniss and Goleman [29] as a factor that can influence both an individual's response to an event and the subsequent response selection. In this regard, anthropologists also suggest that cultures have conventions and norms that influence the management of emotions in individuals [30]. These cultural values create commonality and predictability among individuals in their interpretation and response to emotional stimuli. Past research has shown that Whites score lower on EI tests than Hispanics and Blacks [30], a finding that is not in congruence with the later educational and social achievements. Therefore, it is important to study EI in different cultures and ethnic populations to gain insights into their emotional processes. One conclusion from this assessment could include that, while enhancement of rapport, sympathy and emotional intelligence skills, according to Stoller et al. [27], can be an auspicious enlightening approach, selection of medical students based on EI is a discriminating dogma. Also, too much stress on significance of EI by medical mentors is not reasonable, since still a notable unpredictability exists regarding the subject. Evidence based medicine cannot be established on uncertain grounds. If psychiatric training can make low EI a trifling phenomenon, so it can happen in other areas of clinical practice as well. Anyhow , while small sample size, constrained number of objective assessment tools, restriction of study to merely psychiatric residents, limitation of study to a short period of assessment, lack of control or comparison group were among the weaknesses of this study, which limit the generalization of its results, it was simply a pilot exploration. Additional investigations in future with larger sample populations and more systematized approach will certainly help to explore in this regard more meticulously.

\section{Conclusion}

The current study demonstrates that EI does not seem to be a fixed problem in psychiatric residents, and enough exercise along with improvement of necessary interrogating or clinical skills may improve or compensate for unsatisfactory EI.

\section{References}

1. Ashkanasy NM (2002) Emotion in the workplace: The new challenge for managers. Academy of Management Executive 16(1): 76-86.

2. Bradberry TR, Su LD (2006) Ability versus skill-based assessment of emotional intelligence. Psicothema 18: 59-66.

3. Pérez JC, Petrides KV, Furnham A (2005) Measuring trait emotional intelligence. In R. Schulze and R.D. Roberts (Eds.); International Handbook of Emotional Intelligence. Cambridge: Hogrefe \& Huber, USA.

4. Dulewicz V, Higgs M, Slaski M (2003) Measuring emotional intelligence: Content, construct and criterion-related validity. Journal of Managerial Psychology 18(5): 405-420.

5. Schutte NS, Malouff JM, Hall LE, Haggerty DJ, Cooper JT, et al. (1998) Development and validation of a measure of emotional intelligence. Personality and Individual Differences 25(2): 167-177.

6. Mayer JD, Salovey P, Caruso D, Sitarenios G (2003) Measuring emotional intelligence with the MSCEIT V2.0. Emotion 3(1): 97-105. 
7. Zeidner M, Matthews G, Roberts RD (2004) Emotional intelligence in the workplace: A critical review. Applied Psychology 53(3): 371-399.

8. Ross M, Carroll G, Knight J, Chamberlain M, Fothergill-Bourbonnais F, et al (1988) Using the OSCE to measure clinical skills performance in nursing. Journal of Advanced Nursing 13(1): 45-56.

9. Ziv A, Ben David S, Ziv M (2005) Simulation based medical education: An opportunity to learn from errors. Med Teach 27(3): 193-199.

10. Nelson A (2003) Using simulation to design and integrate technology for safer and more efficient practice environments. Nurs Outlook 51(3): 27-29.

11. Okuda Y, Bryson EO, De Maria S, Jacobson L, Quinones J, et al. (2009) The utility of simulation in medical education: What is the evidence? Mt Sinaii J Med 76(4): 330-343.

12. Holmboe ES, Huot S, Chung J, Norcini J, Hawkins RE (2003) Construct validity of the miniclinical evaluation exercise (MiniCEX). Academic Medicine 78(8): 826-830.

13. Hayden SR, Dufel S, Shih R (2002) Definitions and competencies for practice-based learning and improvement. Acad Emerg Med 9(11): 1242-1248.

14. Jonker CS, Vosloo C (2008) The psychometric properties of the Schutte Emotional Intelligence Scale: Empirical research. South African Journal of Industrial Psychology 34(2): 21-30.

15. Halm BM, Lee MT, Franke AA (2010) Improving medical student toxicology knowledge and self-confidence using mannequin simulation. Hawaii Med J 69(1): 4-7

16. Prince KJ, Boshuizen HP, Van der Vleuten CP, Scherpbier AJ (2005) Students opinion about their preparation for clinical practice. Med Educ 39(7): 704-712

17. Weller JM, Nestel D, Marshall SD, Brooks PM, Conn JJ (2012) Simulation in clinical teaching and learning. Med J Aust 196(9): 594

18. Black PJ, Wiliam D (1998) Assessment and classroom learning. Assess Educ Princ Pol Pract 5(1): 7-74.

19. Thomas K, Donovan B, Cunningham D, Murphy A, Flaherty G, et al. (2012) An Online Management Information System for Objective Structured Clinical Examinations. Computer and Information Science 5 (1): 38-48.
20. Thomas K, Griffin L, Cunningham D, Setyonugroho W, Field CA, et al. (2010) Back to the Future: Electronic Marking of Objective Structured Clinical Examinations and Admission Interviews Using an Online Management Information System in Schools of Health Sciences. Health \& Medical Informatics 6 (1): 1-6.

21. Martin IG, Stark P, Jolly B (2000) Benefiting from clinical experience: the influence of learning style and clinical experience on performance in an undergraduate objective structured clinical examination. Med Educ 34(7): 530-534

22. Carrothers RM, Gregory SW, Gallagher TJ (2000) Measuring emotional intelligence of medical school applicants. Academic Medicine 75(5): 456-463.

23. Stratton TD, Elam CL, Murphy-Spencer AE, Quinlivan SL (2005) Emotional intelligence and clinical skills: Preliminary results from a comprehensive clinical performance examination. Acad Med 80(10): 34- 37.

24. McQueen ACH (2004) Emotional intelligence in nursing work. J Adv Nurs 47(1): 101-108.

25. Arora S, Ashrafian H, Davis R, Athanasiou T, Darzi A, et la. (2010) Emotional intelligence in medicine: A systematic review through the context of the ACGME competencies. Med Educ 44(8): 749-764.

26. Stoller JK, Taylor CA, Farver CF (2013) Emotional intelligence competencies provide a developmental curriculum for medical training. Med Teach 35(3): 243-247.

27. Austin EJ, Evans P, Goldwater R, Potter V (2005) A preliminary study of emotional intelligence, empathy and exam performance in first year medical students. Personality and Individual Differences 39(8): 13951405

28. Cherniss C, Goleman D (2001) The emotionally intelligent workplace. How to select for, measure and improve emotional intelligence in individuals, groups and organizations. San Francisco: Jossey-Bass, USA.

29. Ekman P (1980) The face of man: Expressions of universal emotions in a New Guinea village. New York: Garland STPM Press, USA

30. Roberts RD, Zeidner M, Matthews G (2001) Does emotional intelligence meet traditional standards for intelligence? Some new data and conclusions. Emotion 1(3): 196-231.
(C) (i) This work is licensed under Creative

To Submit Your Article Click Here:

Submit Article

DOI: $10.32474 / 0 J N B D .2019 .03 .000165$

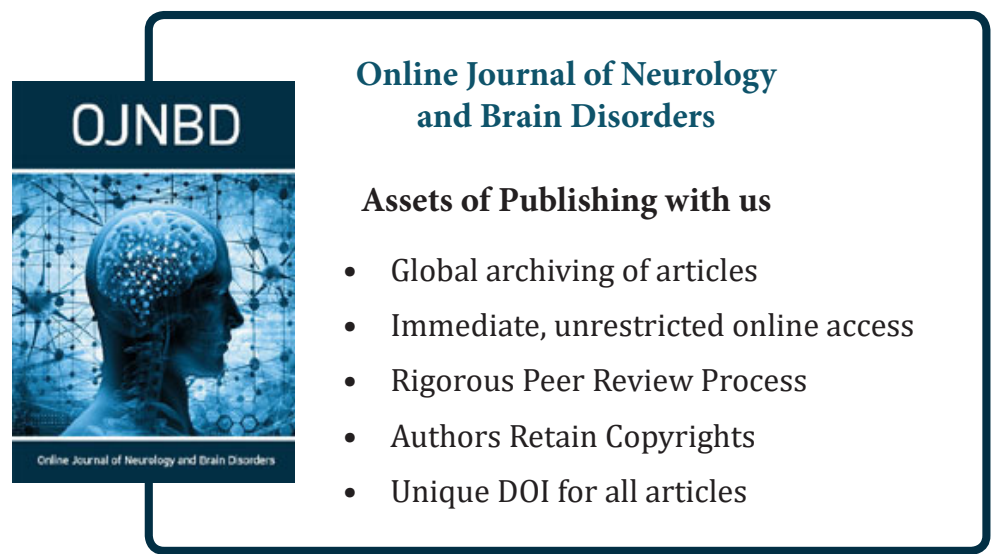

Citation: Saeed Shoja Shafti. Objective Structured Examinations as Supplemental Equipment for Amending Emotional Intelligence: A 